\title{
OPTIMASI PENJADWALAN PERKULIAHAN JURUSAN TEKNIK INFORMATIKA UNIVERSITAS ISLAM NEGERI MAULANA MALIK IBRAHIM MALANG MENGGUNAKAN ALGORITMA GENETIKA DENGAN METODE SELEKSI RANK
}

\author{
M. Ainul Yaqin ${ }^{1}$,Totok Lisbiantoro ${ }^{2}$, \\ Jurusan Teknik Informatika, Fakultas Sains dan Teknologi \\ Universitas Islam Negeri Maulana Malik Ibrahim Malang
}

\begin{abstract}
ABSTRAK
Abstrak-Penjadwalan mata kuliah merupakan hal yang penting dalam proses kegiatan akademik dan juga menjadi suatu permasalahan yang sangat sulit dipecahkan, khususnya pada jurusan teknik informatika UIN Maulana Malik Ibrahim Malang. Dengan keterbatasan dosen yang ada, jumlah kelas dan jumlah ruangan dituntut agar tetap bisa memenuhi kebutuhan pelayanan kepada mahasiswa. Penelitian sebelumnya tentang optimasi penjadwalan perkuliahan menggunakan algoritma genetika dengan metode seleksi Roulette Wheel, belum menunjukkan hasil yang maksimal, terbukti dengan tingkat kesalahan sebesar 27,79\%. Oleh karena itu dengan penelitian ini dicoba untuk memperbaiki penelitian tersebut, yaitu menggunakan algoritma genetika dengan metode seleksi Rank. Selain itu dalam penelitian ini akan dibandingkan hasilnya dengan metode Simulated Annealing.Algoritma genetika merupakan pendekatan komputasional untuk menyelesaikan masalah yang dimodelkan dengan proses biologi dari evolusi, meliputi seleksi, crossover, dan mutasi. Berbeda dengan penelitian sebelumnya di atas yang menggunakan metode seleksi Roulette Wheel, dalam penelitian ini menggunakan metode seleksi Rank, yang sekaligus merupakan perbaikan dari metode seleksi Roulette Wheel. Hasil uji coba menunjukkan bahwa dalam penelitian ini dihasilkan jadwal yang optimal dengan parameter genetikanya yaitu ukuran populasi 10, probabilitas crossover 0,70 dan probabilitas mutasi 0,15. Penelitian ini juga berhasil memperbaiki tingkat kesalahan menjadi $0 \%$. Estimasi waktu penjadwalan rata-rata untuk algoritma genetika pada penelitian ini adalah 3 jam 13 menit 54 detik dalam 5 kali percobaan. Sedangkan pada Simulated Annealing membutuhkan waktu rata-rata 25 menit dengan kondisi jadwal yang sama-sama optimal.Sehingga algoritma genetika dengan metode seleksi Rank dapat digunakan untuk menjadwalkan perkuliahan pada jurusan teknik informatika Universitas Islam Negeri Maulana Malik Ibrahim Malang.
\end{abstract}

Kata Kunci: jadwal, algoritma genetika, metode seleksi Rank 


\section{PENDAHULUAN}

Proses pembuatan jadwal perkuliahan pada jurusan teknik informatika di Universitas Islam Negeri MALIKI Malang saat ini membutuhkan waktu yang relatif lama. Beberapa masalah yang menyebabkan lamanya waktu pembuatan jadwal diantaranya terbatasnya dosen pengampu, ruang, jam mengajar, dan bertambahnya kelas karena semakin bertambahnya mahasiswa disetiap tahunnya serta tuntutan kebutuhan menyebabkan terkadang jadwal yang dibuat masih mangalami pelanggaran terhadap soft constrain dan hard constrain yang ada. Untuk itu perlu dibuat suatu aplikasi yang dapat membantu dalam pembuatan jadwal perkuliahan agar prosesnya lebih cepat dan optimal. Algoritma genetika sudah pernah digunakan pada penelitian sebelumnya oleh Lina Maria Ulfa dengan metode seleksi Roulette Wheel, namun masih belum mampu mengatasi masalah-masalah penjadwalan yang ada, terbukti dengan tingkat kesalahan sebesar 27,79\%. Dalam penelitian ini akan dicoba untuk memperbaiki penelitian tersebut, yaitu menggunakan algoritma genetika dengan metode seleksi Rank, dimana metode seleksi Rank merupakan perbaikan dari metode seleksi Roulette Wheel.

\section{PENERAPAN ALGORITMA}

Algoritma Genetika adalah algoritma yang memanfaatkan proses seleksi alamiah yang dikenal dengan proses evolusi. Langkahlangkah dalam penerapannya pada penjadwalan yaitu:

\section{Representasi Kromosom}

Algoritma Genetika tidak beroperasi dengan penyelesaian asli dari suatu masalah tetapi beroperasi dengan dengan penyelesaian yang telah di representasikan Representasi kromosom merupakan proses pengodean dari penyelesaian asli dari suatu permasalahan. Pengodean kandidat penyelesaian ini disebut dengan kromosom. Pengodean tersebut meliputi penyandian gen, dengan satu gen mewakili satu variabel.

\section{Membangun Generasi Awal}

Langkah ini membentuk sejumlah populasi awal yang digunakan untuk mencari penyelesaian optimal. Populasi awal yang dibangun dalam tugas akhir ini dengan menggunakan bilangan random (acak) dengan range bilangan yang telah ditentukan.

\section{Fungsi Fitness}

Fungsi fitness digunakan untuk proses evaluasi kromosom agar diperoleh individu yang diinginkan. Fungsi ini membedakan kualitas dari individu untuk mengetahui seberapa baik individu yang dihasilkan. Semakin tinggi nilai fitness akan semakin besar kemungkinan individu tersebut terpilih ke generasi berikutnya.

\section{Seleksi}

Setiap individu yang terdapat dalam populasi akan melalui proses seleksi untuk dipilih menjadi orangtua. Seleksi adalah suatu proses yang digunakan untuk memilih individu-individu yang akan digunakan pada proses generasi berikutnya dengan mempertimbangkan nilai fitness.

\section{Crossover}

Crossover atau persilangan merupakan operasi yang bekerja untuk menggabungan dua individu hasil seleksi menjadi individu baru. Tidak semua individu mengalami persilangan karena ditentukan oleh paramater yang disebut dengan crossover rate atau probabilitas persilangan.

\section{Mutasi}

Setelah crossover dilakukan, proses reproduksi dilanjutkan dengan mutasi. Hal ini dilakukan untuk menghindari solusisolusi dalam populasi mempunyai nilai lokal optimum. Mutasi adalah proses mengubah gen dari keturunan secara random. 


\section{Kondisi Berhenti}

Proses ini akan berhenti jika kondisi berhenti terpenuhi, jika tidak maka akan kembali ke langkah 3.

\section{IMPLEMENTASI}

Berikut adalah flowchart untuk tahapan implementasi:

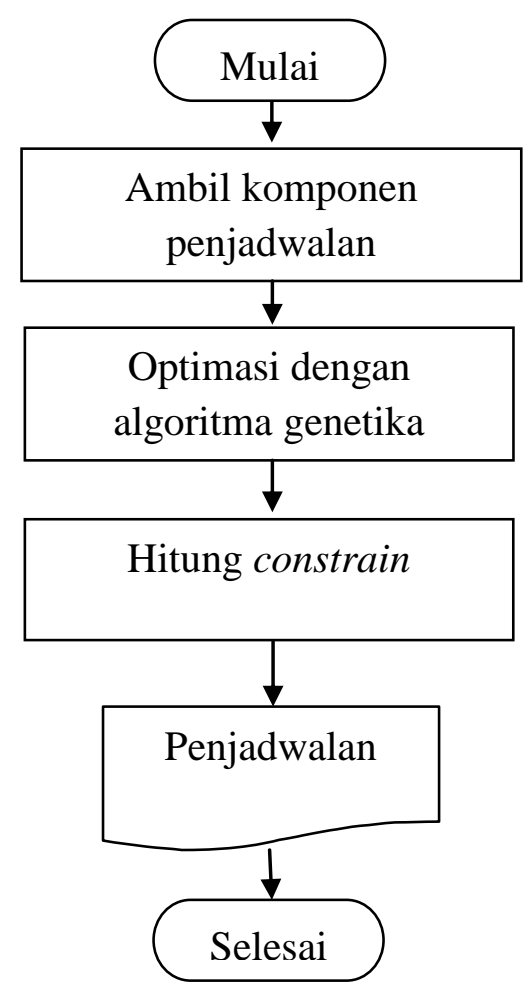

Gambar 1. Flowchart tahapan implementasi

\section{Komponen Penjadwalan}

Komponen penjadwalan yang dimaksud adalah data-data penjadwalan yang nantinya akan dikodekan sehingga dapat diproses oleh algoritma genetika. Datadata tersebut meliputi data dari tabel pengampu yang berisi mata kuliah, kelas, dan dosen pengampu, tabel hari, tabel jam yang berisi slot waktu, dan tabel ruang.

\section{Optimasi dengan Algoritma Genetika}

Langkah pertama yang dilakukan yaitu mengodekan data-data yang telah diambil. Untuk rancangan kromosomnya terdiri dari 4 komponen penjadwalan, yaitu mata kuliah dari tabel pengampuan, jam kuliah, hari, dan ruang, seperti pada gambar berikut:

\begin{tabular}{|l|l|l|l|}
\hline MK & Jam & Hari & Ruang \\
\hline
\end{tabular}

Gambar 2. Rancangan kromosom

Membangkitkan populasi awal yang diperoleh secara random sehingga didapatkan solusi awal. Populasi itu sendiri terdiri dari sejumlah individu yang merepresentasikan sejumlah solusi. Populasi tersebut dicek nilai fitnessnya untuk tahap selanjutnya yaitu seleksi. Dalam penelitian ini digunakan metode seleksi Rank, yang merupakan perbaikan dari metode seleksi Roulette Wheel karena pada seleksi Roulette Wheel kemungkinan salah satu kromosom mempunyai nilai fitness yang mendominasi hingga $90 \%$ bisa terjadi, sehingga nilai fitness yang lain akan mempunyai kemungkinan yang sangat kecil sekali untuk terpilih, sedangkan dalam seleksi rank dilakukan perumpamaan sesuai dengan nilai fitnessnya, nilai fitness terkecil diberi nilai 1 , yang terkecil kedua diberi nilai 2, dan begitu seterusnya sampai yang terbesar diberi nilai N. Nilai tersebut yang akan diambil sebagai prosentasi tepat yang tersedia. Dari proses seleksi didapatkan induk untuk proses crossover. Crossover yang digunakan pada penelitian ini adalah crossover 2 titik. Crossover 2 titik ini adalah crossover pada 2 titik tertentu yang ditentukan secara random, misalkan dalam 1 individu terdapat 6 kromosom, jika 2 titik yang keluar adalah 2 dan 4 maka kromosom 1 tetap, kromosom 2 sampai 4 ditukar, dan kromosom 5 sampai 6 tetap. Setelah crossover selesai, didapatkan individu-individu baru yang akan dimutasi sesuai dengan probabilitas mutasinya. Mutasi dilakukan dengan cara merandom ulang komponen penjadwalan, jika proses mutasi selesai maka di hitung nilai fitness masing-masing individu, jika belum ada yang sesuai dengan batasan-batasan yang ditentukan maka akan diulang ke proses 
seleksi sampai mutasi sehingga ditemukan solusi yang sesuai. Batasan-batasan dalam penelitian ini adalah:

1. Tidak ada dosen yang mengajar lebih dari satu kelas mata kuliah pada waktu yang sama

2. Tidak ada dua kelas mata kuliah yang berbeda diselenggarakan bersamaan di satu ruangan

3. Mata kuliah semester 1 dan 2 dimulai jam 08.00 sampai jam 14.00

4. Mata kuliah semester 1 dan 2 menggunakan sistem paket, sehingga tiap mata kuliah tidak boleh dijadwal pada waktu yang sama untuk kelas yang sama

5. Waktu sholat jum'at tidak boleh ada perkuliahan

6. Waktu kesediaan dosen lebih diutamakan, namun jika terpaksa tidak bisa, boleh diabaikan

7. Tidak ada perkuliahan yang dimulai pada waktu dhuhur, namun jika terpaksa tidak bisa, maka boleh diabaikan

\section{HASIL UJI COBA}

Pengujian dilakukan berdasarkan parameter genetika yang disarankan pada beberapa literatur yang telah diuji coba kembali untuk menentukan parameter yang benar-benar sesuai pada masalah penjadwalan ini. Berikut hasil rekap percobaan yang dilakukan:

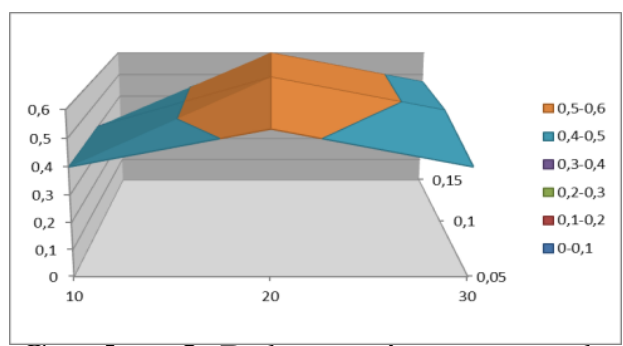

Gambar 3. Rekap rasio error prob.

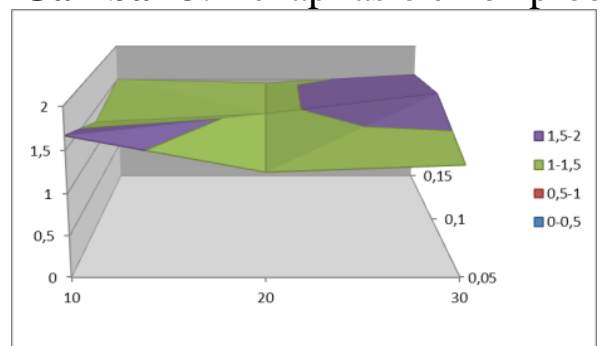

Gambar 4. Rekap rata-rata error prob. crossover

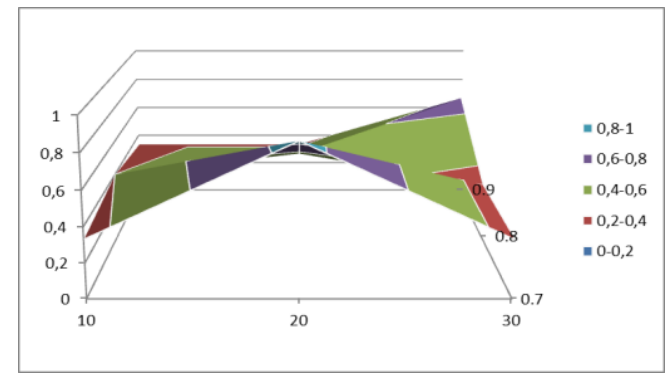

Gambar 5. Rekap rasio error prob. mutasi

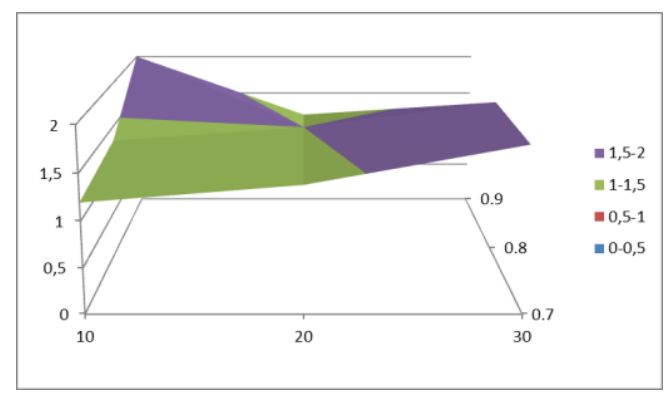

Gambar 6. Rekap rata-rata error prob. mutasi

Data yang digunakan adalah pemasaran mata kuliah sebanyak 156, 7 ruang kuliah, dan 6 hari dengan masing-masing 13 slot waktu. Dari beberapa percobaan di atas, ditemukan parameter yang sesuai sebagai berikut:

\begin{tabular}{|l|c|}
\hline \multicolumn{1}{|c|}{ Parameter } & Nilai \\
\hline Individu per populasi & 10 \\
\hline Probabilitas crossover & 0.7 \\
\hline Probabilitas mutasi & 0.15 \\
\hline
\end{tabular}

Tabel 1. Parameter genetika

Parameter tersebut digunakan pada pengujian sebanyak 5 kali. Berdasarkan pengujian yang telah dilakukan, tingkat kesalahan jadwal perkuliahan yang dihasilkan sebesar $0 \%$, dengan waktu ratarata 3 jam 13 menit 54 detik, sehingga dapat disimpulkan bahwa penelitian ini berhasil menangani masalah-masalah penjadwalan hingga $100 \%$. 


\section{Analisa dengan Simulated Annealing}

Jika dibandingkan dengan Simulated Annealing dengan menggunakan data dan batasan-batasan yang sama, Algoritma Genetika memerlukan waktu yang lebih lama dalam prosesnya, waktu rata-rata Simulated Annealing hanya 25 menit, namun untuk tingkat keakuratannya relatif sama.

\section{KESIMPULAN DAN SARAN}

\section{Kesimpulan}

1. Algoritma Genetika dapat digunakan sebagai alternatif solusi untuk menyelesaikan masalah penjadwalan perkuliahan

2. Metode seleksi Rank dapat memperbaiki kesalahan yang ditimbulkan oleh metode seleksi Roulette Wheel

3. Untuk masalah kecepatan proses, Simulated Annealing unggul dibandingkan Algoritma Genetika, namun untuk tingkat keakuratannya sama

\section{Saran}

1. Ruang lingkup dalam penelitian ini masih di tingkat jurusan, sehingga dapat diperbesar hingga ke tingkat universitas.

2. Penggunaan metode lain yang mungkin lebih sesuai atau menggunakan metode hibrid

\section{DAFTAR PUSTAKA}

1. Dibyo L, Heru. 2010. Optimasi Penempatan Kapasitor Pada Sistem Tenaga Listrik Dengan Menggunakan Algoritma Genetik. http://

herudibyolaksono.files.wordpress.c om/2010/07/jurnal_7.pdf. Diakses: pada 6 Maret 2011

2. Edmund Burk, dkk. Automated University Timetabling: The State of the Art.University of Nottingh
3. Edward L. Mooney, dkk. 1995 LARGE SCALE CLASSROOM SCHEDULING. Industrial and Management Engineering Department, Montana State University.

4. Kadir, Abdul. 2002. Pengenalan Sistem Informasi. Yogyakarta: Penerbit Andi

5. Kusumadewi,Sri. 2003. Artificial Intelligence. Yogyakarta: Graha Ilmu .

6. Kusumadewi, Sri dan Purnomo, Hari. 2005. Penyelesaian Masalah Optimasi dengan Teknik-teknik Heuristik. Yogyakarta:Graha Ilmu

7. Maria Ulfa,Lina.2011. Optimasi Penjadwalan Perkuliahan Menggunakan Algoritma Genetika. Universitas Islam Negeri Maulana Malik Ibrahim Malang: Jurusan Teknik Informatika.

8. Nurul,Anisty F. 2011. Rancang Bangun Aplikasi Prediksi Jjumlah Penumpang Kereta Api Menggunakan Algoritma Genetika.www.eepisits.edu/uploadta/downloadmk.php? $\mathrm{id}=1392$. Diakses: pada 6 Maret 2011

9. Otbiko, M. 1998. Genetic Algorithms.

http://www.obitko.com/tutorials/ge netic-algorithms/, Diakses: pada 6 Maret 2011

10. Paseru, Debby, dkk. 2007. Sistem Informasi Pengaturan Jadwal Mata Kuliah (Studi Kasus : Universitas Katolik De La Salle Manado). Intstitut Teknologi Bandung: Jurusan Teknik Informatika

11. Ponnambalan, S.G., Jawahar, N., and Aravindan, P., 1999. "A Simulated Annealing Algorithm for Job Shop Scheduling", 
12. Production Planning and Control, Vol. 10, No.8, 767-777.

13. Purwowibowo. 2008. Peningkatan Akurasi Linear Trnsducer Menggunakan Genetic Algorithm dan Golden Ratio Segmentation. http://www.lontar.ui.ac.id/file?file= digital/129075-

T+24256++Peningkatan+akurasi.p df Diakses: pada 6 Maret 2011

14. Riyanto, dkk. 2008. Pengembangan Aplikasi Manajemen Database.Yogyakarta: Gava Media

15. Munir, Rinaldi. Strategi. 2006. Algoritmik, Program Studi Informatika STEI Institut Teknologi Bandung,Bandung,

16. Spyros Kazarlis Vassilios Petridis and Pavlina Fragkou. Solving University Timetabling Problems Using Advanced Genetic Algorithms. Technological Educational Institute of Serres, Serres 62124 Greece dan Aristotle University of Thessaloniki, Thessaloniki 540 06, Greece

17. Suryosubroto B. 2004. Manajemen Pendidikan di Sekolah. Jakarta. PT Asdi Mahasatya

18. Suyanto. 2005.Algoritma Genetika dalam MATLAB.ANDI.Yogyakarta.

19. Widyadana, I Gede Agus dan Pamungkas, Andree. 2002. Perbandingan Kinerja Algoritma Genetika Dan Simulated Annealing Untuk Masalah Multiple Objective Pada Penjadwalan Flowshop. Universitas Kristen Petra:Fakultas Teknologi Industri, Jurusan Teknik Industri 
